\title{
Application of Education Informatization Promoting Educational Equity in Remote Areas of China
}

\author{
Sijia Kou
}

\begin{abstract}
Nowadays, an increasing number of people are concerned about the problem of educational inequality. Especially in remote areas in China, due to the backward development of the economy, the population is outflowing, which means that the teachers are not strong enough. Meanwhile, the science and technology are not advanced enough and the infrastructure construction is not perfect. With the continuous development of information technology, education informatization has brought more and more attention to education equity. Poverty reduction through education is a hot issue that the Ministry of Education of the People's Republic of China is concerned about. The education informatization we mentioned in this paper points to fundamental education informatization. This article has introduced the fundamental educational performance of China and the contribution of one of the Chinese projects, which is named cross-regional simultaneous teaching application pilot project, to improve teaching quality in terms of educational technology making use of the two-way broadband satellite and the platform called panoramic learning platform. This means that teachers and students, especially for remote areas' teachers and students, can benefit from this project to gain more educational resources. By harnessing this, China can help more people to receive a better education so that it can bridge the gap between rich and poor.
\end{abstract}

Index Terms-Cross-regional simultaneous teaching application pilot project, education informatization, panoramic learning platform, two-way broadband satellite.

\section{INTRODUCTION}

With the development of the Internet and Information technology, education informatization has attracted more and more attention in recent years [1]. The 19th National Congress of the Communist Party of China pointed out that the Chinese government should pay more attention to the development of education and improve relevant infrastructure construction, and therefore every child is able to have a fair and quality education [2]. It is known that education informatization is one of the most effective approaches to improve the quality of education [3]. Additionally, it is the most realistic choice to solve educational poverty alleviation [4]. The reason is that time and space constraints can be broken through education informatization. Meanwhile, education informatization has many other advantages. For example, it can spread quickly, and it has abundant means of ways to present [5]. Thus, education informatization could be an advanced method to

Manuscript received December 19, 2019; revised March 7, 2020. This work was supported in part by the Ministry of Education.

Sijia Kou is with the National Center for Education Technology, 160 Fuxingmennei Street, Bejing, China (e-mail: kousj@moe.edu.cn). implement the equality of education.

The contribution of this article is to introduce a Chinese project to bridge the digital divide so that education informatization can help students in remote achieve educational equality [6]. The problems can be considered in four elements. Firstly, the poverty-stricken areas' students cannot learn all kinds of courses especially for Music, Art, English and other courses [7]. Secondly, although 94\% of primary and secondary schools have Internet access, over 8,000 schools still have no Internet access (the Ministry of Education [MOE], China, 2018). Thirdly, quality resources are lacked in a remote place. Last, some teachers in the poverty-stricken areas are not up to the standard of quality teaching [8]. In order to solve these problems, the Chinese government launches a pilot program for cross-regional synchronous teaching. The pilot project uses the most advanced Internet technology to introduce famous teachers from famous schools to primary schools in resource-deficient areas. Moreover, the Ministry of Education has organized the use of China's newest two-way broadband satellites and panoramic learning platform in this project to speed up the full coverage of school broadband network and solve the "last meter" of Internet access.

\section{AN OVERVIEW OF THE FUNDAMENTAL EDUCATIONAL PERFORMANCE OF CHINA}

Since the establishment of the People's Republic in 1949, China has achieved remarkable results in education [9]. From 1949 to 2019, it passed three major historical stages. The first stage was from the founding of the People's Republic of China to 1966, which is often referred to as the "17-year" period, and it was also the foundation period for fundamental education. The period of the "Cultural Revolution", which was called the second stage, was a period of setbacks and difficulties from 1966 to 1976 . The third stage is from 1977 to the present, and the fundamental education has entered the period of strategic development since the reform and opening up and this year is the 70th year of primary education [10].

The first stage was the period of comprehensive recovery and development of fundamental education. According to the "Common Program of the Chinese People's Political Consultative Conference" in 1949, the People's Republic of China is a national, scientific, and mass cultural education country to improve the people's cultural level, cultivate the country's construction talents, and eliminate feudal, comprador, and fascism. The most striking feature is that under the socialist system, the new socialist education has been established. Besides, the fundamental education reform based on the new educational experience in the old liberated 
areas, the useful experience of absorbing old education, and the use of Soviet experience to build a new-democratic education has been established. Education opened to the workers and peasants, carried out literacy and literacy education, and opened industrial and agricultural schools, tutorial schools and crash schools. Education opened to the workers and peasants, carried out literacy and literacy education, and opened industrial and agricultural schools, tutorial schools and crash schools. At the beginning of the People's Republic of China, $80 \%$ of the country's 450 million people were illiterate, and the enrollment rate of school-age children was only $20 \%$ [10]. By the end of 1965 , the number of secondary school students reached 14.32 million, and the number of primary school students reached 1,162,900, which was 6.9 times and 3.9 times higher than the highest in 1946 before the founding of the People's Republic of China. From 1949 to 1965 , the country wiped out 192,233,000 illiterate people, and the average annual literacy was 6,043,000 [10]. In 1951, the Government Council announced the "Decision on Reforming the Academic System", and the new academic system began to be unified, and then a professional team of teachers was initially formed. By 1965, there were 5.55 million faculty members in large, middle, and primary schools and kindergartens nationwide, five times more than before 1949, and adapted to the basic needs of educational development. In the content and methods of education and teaching, extensively study the Soviet model and improve the teaching level of primary education.

The second stage was the period of painful setbacks in the "Cultural Revolution". Under such difficult circumstances, the majority of teachers and educators were loyal to the people's educational cause and made a determined struggle with the "Gang of Four" group, who were insisting on education and teaching, nurturing the next generation, and saving useful educational power. The ideas and practices of streamlining basic education, shortening the academic system, weakening the examination, and learning to work and educate in the "Cultural Revolution" have had far-reaching adverse effects on fundamental education [11].

The third stage is the period of reform and opening up, three-dimensional and multi-dimensional strategic development, which embodies the historical achievements of 70 years of fundamental education reform and development. In this period, China is paying more attention to fundamental education so that the country orderly and intensively introduces essential policies and laws, and forms a fundamental education development strategy and key node policy. The development of fundamental education at this stage is characterized by linear to circular development, which is forming a linear development along the popular primary, middle and high school education, and then returning to universal preschool education, and finally achieving closed-loop development. China began to provide support for the development of urban higher education (including higher vocational education) and economic science and technology culture. In the later period, China will focus on promoting education in rural, remote and minority areas, weak schools, education for poverty alleviation, and the development of left-behind children [12]-[14].

\section{THE Methods FOR EQUALITY EDUCATION}

In order to help grass-roots schools in resource-scarce regions solve the problematic tasks of real work and quickly promote the concept of "perfect each school and teach every student", the project called "cross-regional simultaneous teaching application pilot project" has been launched from 2016 until now. The pilot project utilized the most advanced Internet technology to introduce famous teachers into primary school classrooms in resource-poor areas. The effect is implementing the automatic recording function of pre-school and after-school teaching sessions, collecting big data, establishing a teaching analysis system, helping school teachers to provide information and tools for learning feedback, and promoting the application of big data to improve teaching quality. It is useful to explore effective mechanisms for optimizing investment in education and use information technology to expand the coverage of quality educational resources. Our government conducted cross-regional pilot projects in Tongxiang City, Zhejiang Province, Binzhou City, Qingzhou City, Shandong Province, and Dazhou City, Sichuan Province. Through the Internet, special delivery classes are set up. Local school students experience lessons in schools in Shanghai and other regions through the panoramic teaching platform. They are well received by school teachers and students, enabling local teachers and students to learn and experience the curriculum of Shanghai and other schools. Educated regions and weak regions will be guided to achieve twinning and assistance through education informatization, narrow the gap between regions, urban and rural areas, and school-level gaps, and link educational digital divides to achieve fair and quality education.

After organizing famous teachers to go to the pilot county to exchange, teachers carry out synchronous teaching and research [15], [16]. The teachers of the famous schools use the guiding function of the platform to release a teaching plan of the unit in advance, and the synchronous pilot class and other pilot class teachers (this pilot class teachers referred to as experimental teachers) participate in the seminar asynchronously to realize the collective network preparation. The platform collects teachers' opinions and provides them to the team of famous teachers. On the basis of the discussion, teachers shall decide on the teaching plan in the form of live class and collective discussion with the experimental teachers on the platform at the appointed time. Meanwhile, students' pre-test and guidance shall be formulated. The process of class before the class is shown in Fig. 1.

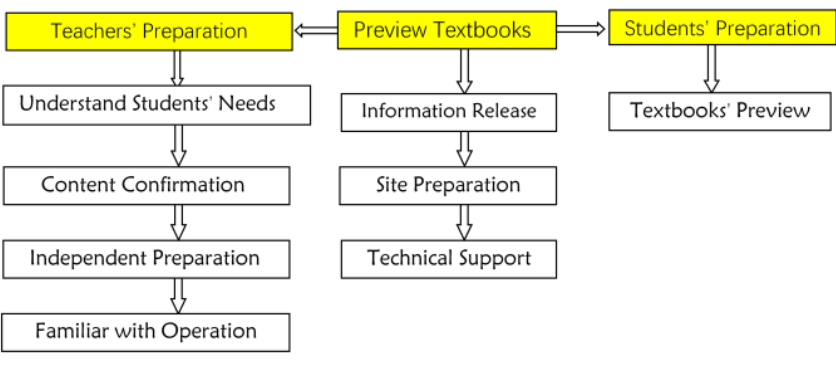

Fig. 1. Pre-class preparation.

Moreover, demonstration classes should be open. In this 
process, the teachers from developed areas select the first unit lesson and the unit summary lesson as the model lesson for each unit of knowledge. Under the cooperation of experimental teachers, synchronous teaching can proceed by the pilot school through the network using platform which consists of PAD and panoramic learning platform. Teaching data can be recorded through the following aspects: teaching questions and answers, on-screen operation, review assignments and so on. In the demonstration classes, the experimental teachers participate in teaching as teaching assistants. According to the teaching consensus of synchronous teaching and research, they assist the teaching teachers to arrange and organize student activities in the class to ensure that the students in the experimental schools can share and interact with the teaching teachers in real time, and the teaching communication is smooth, so as to realize the student-centered teaching. The diagram of this pattern is given in Fig. 2.

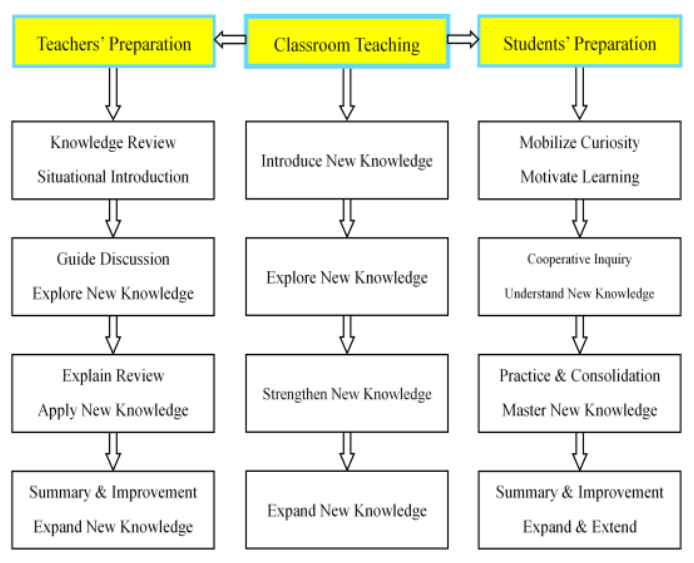

Fig. 2. The teaching procedure.

After the demonstration class has been ended, the pilot schools could open local synchronized classrooms [17]. On the basis of demonstration classrooms and simultaneous teaching and research, each school's experimental teachers will teach other courses in addition to the demonstration classes in the pilot classes, and unify other classes in other pilot schools to simultaneously learn or order online recording courses, and arrange operations in a unified manner. At last, it is vital to conduct after-class discussion, which includes that the experimental teachers record the classroom live uploading platform, and the experimental teachers' comments on each other, the teachers from developed areas in China summarize and guide these courses [18]. The teaching flow is shown in Fig. 3.

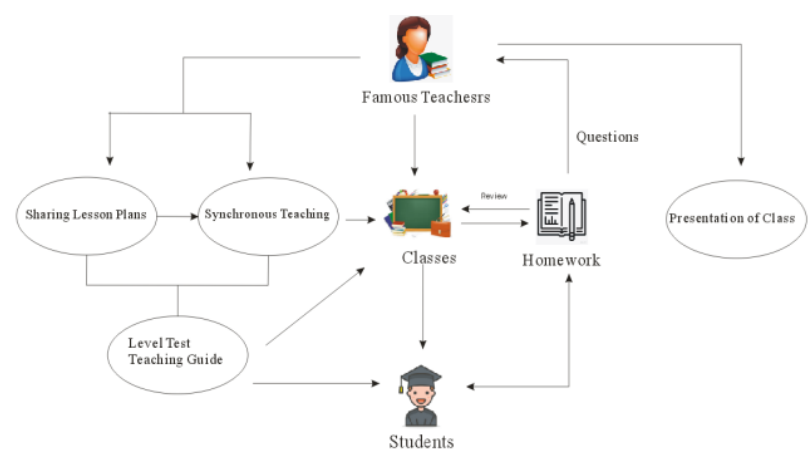

Fig. 3. Teaching flow chart.
In this project, there are two technical means to achieve these goals. One is that the Ministry of Education has organized the use of China's newly launched two-way broadband satellites to speed up full coverage of school broadband networks and solve the "last mile" of the Internet; the other is that exploiting panoramic learning platform to realize the transmission of educational resources is vital to transmit quality education resources better.

\section{A. The Two-Way Broadband Satellite}

The construction of broadband network access and network teaching environment in schools with relatively developed economies has basically been realized, and the mechanism for building a network teaching environment for weak schools has been basically established. However, broadband Internet access in schools in rural areas, remote areas and concentrated areas in the central and western regions have not been effectively resolved. Most of the schools that are not connected to the Internet are in remote areas, with a small population, economic backwardness, and difficulty in network construction, high input costs, low operating income and even the possibility of losses. At present, the Internet access rate for primary and secondary schools in China has reached 94\% (the Ministry of Education [MOE], China, 2018). Due to geographical restrictions, remote rural areas and contiguous More than 8,000 schools in the regional schools (teaching points) are not allowed to access the internet. At present, in some parts of the central and western regions, the full coverage of the school's broadband network is basically achieved. In this condition, it is necessary to explore the use of two-way broadband satellites to solve the problem of Internet access to Internet schools that are difficult to access, up to full coverage of school broadband networks, and help schools in remote areas to share quality resources.

The two-way broadband satellites have the advantages of high efficiency, low-cost small terminals, rapid deployment, and easy maintenance compared with the previously used direct broadcast satellites [19]. The direct broadcast satellites have a low bandwidth rate and need to build a large-scale base station and cannot be interactive. The bidirectional broadband satellites can reach $10 \mathrm{M}$ bandwidth and require only a small base station to interact with each other (the Ministry of Education [MOE], China, 2018). Satellite terminals are low in price and large-scale infrastructure is not required which means that satellite terminals only require utility power. The integrated terminals directly convert the satellite signal into IP data with the network cable as the carrier [20]. Moreover, the two-way broadband satellites have small terminals, and the traditional satellites' terminal need 1.8 meters, and these terminals only need 0.75 meters. At the same time, this kind of terminals can be deployed quickly only demanding two engineers installed and almost two hours for one. It is expected that by 2020, a comprehensive service of broadband networks in schools in remote areas will be implemented. At present, the three counties of Gansu Zhouqu, Leibo of Sichuan, and Yanliang of Yunnan have been selected as pilots to explore the use of two-way satellites to solve the problem of Internet access in Internet schools that are difficult to access. Fig. 4 below 
demonstrates the Two-way Broadband Satellite was built in remote and undeveloped areas.

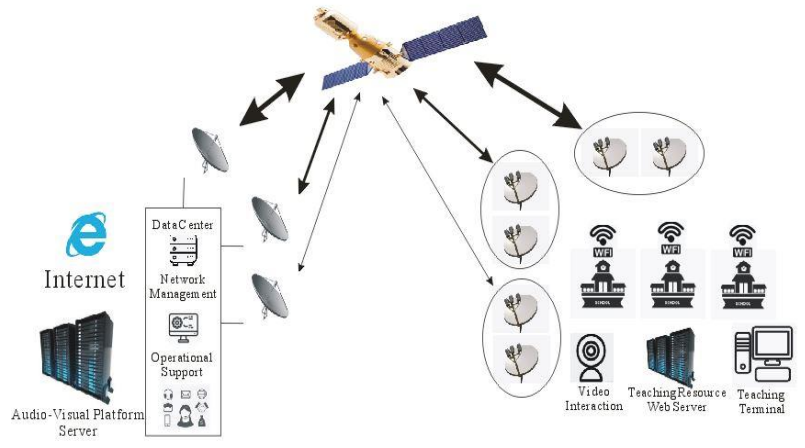

Fig. 4. Two-way broadband satellite.

\section{B. The Panoramic Learning Platform}

The panoramic learning platform is a modern teaching tool based on low-bandwidth transmission, shared interaction, companion data collection and automatic generation of formatted courseware [21]. It is the first innovative research achievement at home and abroad and a significant breakthrough in modern educational technology and the future direction of development [22]. At present, education informatization mainly relies on the technical model of "high-bandwidth Internet + video + plug-in interaction". Limited by current network bandwidth, hardware device cost, and video file technology, education informatization is challenging to promote and apply on a large scale and in a normal manner. And it is inconvenient to conduct remote real-time interactive teaching in WAN environment and collect relevant data to analyze teaching behavior and teaching effects. Besides, video files are too large so that the Internet cannot transmit them smoothly. Platform has an unmatchable advantage so that it should be imported in this project [23].

There are four superiorities about the panoramic learning platform. The first one is that the panoramic learning platform can make teaching resources transmit low bandwidth and low network traffic. IPPT compression technology can compress the original lectures to $1 / 10$ size, and the special format file is $1 / 32$ of the HD video courseware [22]. The platform has low requirements on network equipment and network bandwidth, and the two-way interactive transmission only needs $20 \mathrm{k} / \mathrm{s}$, which can be deployed and applied on a large scale in the case of existing equipment and networks [3]. The second advantage is that this platform can provide "Blackboard Climbing" sharing interaction, which means teachers and students simultaneously perform interactive operations such as writing and drawing on the same "blackboard", and can also perform in-depth interactive sharing teaching such as raising hands and asking questions. In this process, the traditional classroom habits have been maintained, which greatly mobilized the students' interest and made the teaching situation more vivid and interesting. Thirdly, digital courseware can be provided to show students and other teachers. Under national requirements for information security, automatic generation of dedicated panoramic digital courseware is automatically collected so that the generated courseware interface is clear, with good scalability and content irretrievability, and its security function in the process of lectures. Last but not least, the system analyzes the collection of teaching behavior and educational behaviors in this process. In the whole teaching process, the system automatically collects the process data of teachers and students, forms the classroom teaching data source, and provides the basis for the objective automatic generation and analysis of educational big data [22].

\section{RESUlTs}

With the advanced equipment of educational information and leading-edge technology of educational information, this project has excellent results and some shortcomings. The educational hardware facilities have improved, which means that the problem of the pilot schools cannot be covered by the terrestrial network is basically solved [11]. In addition to this, the concept of educational informatization, which teachers established, has been moved to practice. However, this method is not fully inspiring the enthusiasm and vitality of all students in research.

Doctor Zhao took random samplings (212 primary school students) for pilot schools' five classes in three schools in 2018 [24]. Survey respondents are from various provinces and the ratio of male, and female is basically the same so that the results of research is accurate.

There are two aspects including the degree of subjects preference among students and the feedbacks in synchronous curriculum [24]. Focusing on the students' preference for the four subjects of Chinese, mathematics, English and music, the survey found that the synchronized curriculum project is trendy among students. In comparison, students like math most, then music, and then Chinese. The reason why they dislike English most is that English is taught entirely in English. Students cannot understand the spoken language of teachers. However, it is not the case at all. Students like mathematics because mathematics teachers like to teach through small stories to improve the fun of mathematics learning [24]. As can be seen in Fig. 5 and Table I, they represent the number and frequency of students' interest in the pilot subjects.

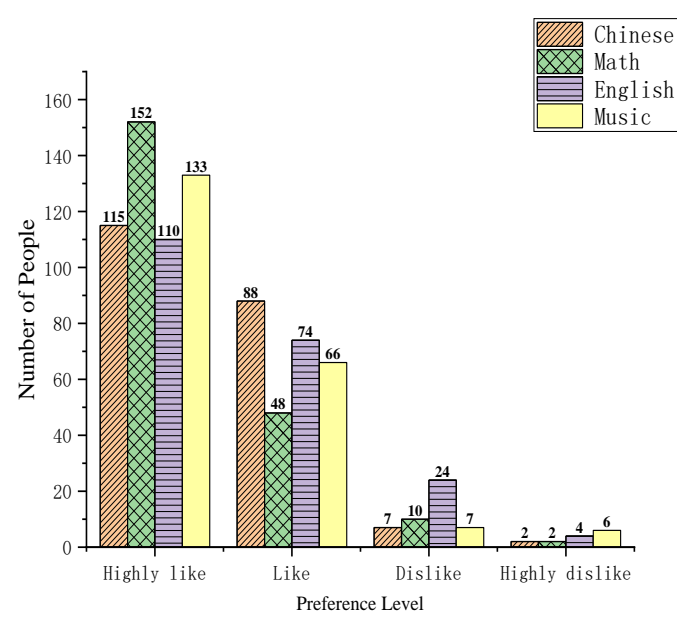

Fig. 5. The number of students' interest [24]. 
TABLE I: THE FREOUENCY OF STUDENTS' INTEREST [24]

\begin{tabular}{|c|c|c|c|c|}
\hline $\begin{array}{c}\text { Subject } \\
\text { Preference Level }\end{array}$ & Chinese & Math & English & Music \\
\hline Highly like & $54.2 \%$ & $71.7 \%$ & $51.9 \%$ & $62.7 \%$ \\
\hline Like & $41.5 \%$ & $22.6 \%$ & $34.9 \%$ & $31.1 \%$ \\
\hline Dislike & $3.4 \%$ & $4.8 \%$ & $11.3 \%$ & $3.4 \%$ \\
\hline Highly dislike & $0.9 \%$ & $0.9 \%$ & $1.9 \%$ & $2.8 \%$ \\
\hline
\end{tabular}

An important manifestation of the interaction of the course is the teacher's questioning to the students in the classroom. However, few students are actively asked by teachers in this kind of class, which means that students have little interaction with the teacher [24]. As can be seen in Fig. 6, few students are asked in the music class, but teachers always ask more questions to students in the Math class. The figures can be seen below.

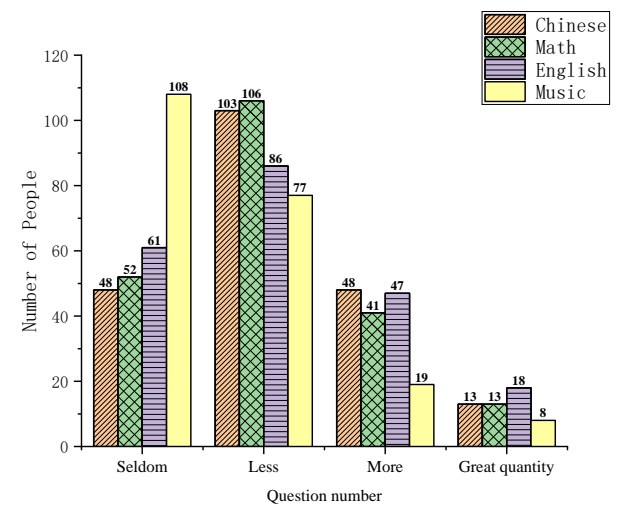

Fig. 6. The number of students questioned by teachers [24].

TABLE II: THE NUMBER OF STUDENTS QUESTIONED BY TEACHERS [24]

\begin{tabular}{|c|c|c|c|c|}
\hline Question number & Chinese & Math & English & Music \\
\hline Seldom & $22.6 \%$ & $24.5 \%$ & $28.8 \%$ & $50.9 \%$ \\
\hline Less & $48.6 \%$ & $50.0 \%$ & $40.5 \%$ & $36.3 \%$ \\
\hline More & $22.6 \%$ & $19.3 \%$ & $22.2 \%$ & $9.0 \%$ \\
\hline Great quantity & $6.2 \%$ & $6.2 \%$ & $8.5 \%$ & $3.8 \%$ \\
\hline
\end{tabular}

As can be seen in Table II, this chart shows the situation of the students being questioned by the teachers in the classroom, reflecting the teacher's mastery of the classroom and student interaction when preparing the teaching content. There are not only good feedbacks but also having some shortcomings. We are expecting the teachers could communicate with students while paying attention to the progress of teaching because the learning situation of the students in the classroom can be tested by teachers after questioning, so as to solve the problems of the students in time.

The figure above and the table below show the questions submitted by the students reflecting the student side of the active participation of the classroom. As can be seen in Fig. 7, few students have questions in the music class, but more students are interested in the Chinese and Math class. The number of students' questions shows students' understanding and thinking about the content of the class, and reflects the degree of attraction of the class content to the students. As can be seen in Table III, it shows the proportion of the number of students taking initiative to ask teachers and we can get the same results as the Fig. 7 .

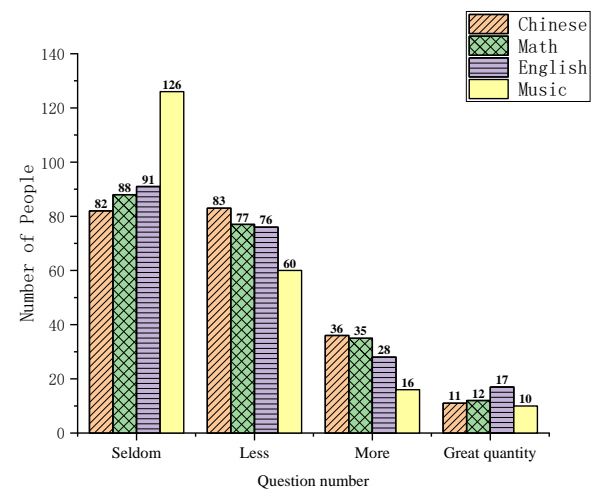

Fig. 7. The number of students taking the initiative to ask teachers [24].

TABLE III: THE NUMBER OF STUDENTS TAKING THE INITIATIVE TO ASK

\begin{tabular}{|c|c|c|c|c|}
\hline \multicolumn{5}{|c|}{ TEACHERS [24] } \\
\hline $\begin{array}{l}\text { Subject } \\
\text { Question number }\end{array}$ & Chinese & Math & English & Music \\
\hline Seldom & $38.7 \%$ & $41.5 \%$ & $42.9 \%$ & $59.4 \%$ \\
\hline Less & $39.1 \%$ & $36.3 \%$ & $35.9 \%$ & $28.4 \%$ \\
\hline More & $17.0 \%$ & $16.5 \%$ & $13.2 \%$ & $7.5 \%$ \\
\hline Great quantity & $5.2 \%$ & $5.7 \%$ & $8.0 \%$ & $4.7 \%$ \\
\hline
\end{tabular}

\section{FACED PROBlems AND SOlved Plans}

Although this project gets gratifying results which provides development opportunities for undeveloped areas, some problems occurred at the same time. There are three main points including the practical difficulties of experimental teachers, students and class time [25].

Firstly, experimental teachers do not have a deep understanding of the project, which means that some of them cannot adapt themselves to the development of education informatization [25]. Meanwhile, the experimental teachers are not familiar with the way of the synchronous course, resulting in a negative attitude. After this project, the experimental teachers' teaching workload has increased, but the salary has not been adjusted. Besides, the famous teachers and the experimental teachers' cooperation ability need to be enhanced. Sometimes, two kinds of teachers have not had effective communication before and after class, and famous teachers cannot assist the experimental teachers in solving problems about students [25]. Secondly, it is difficult to choose the teaching time so that synchronous class time is lack of regularity. Some students said they did not know the class schedule before and some famous teachers' teaching contents are beyond understanding for them. Moreover, long-distance teaching often appears voice are not synchronized, so students cannot interact effectively with the famous teachers. The problem of unsynchronized sounds affects the efficiency and effect of teaching.

In order to solve these problems, measurements should be taken. The Chinese government will hold regular training on how to improve teachers' understanding of the project and how to participate in the teaching during the project so that experimental teachers can understand the purpose of the 
project and apply the panoramic learning platform more skillful. At the same time, the project work of experimental teachers should be included in the assessment and evaluation of teaching, especially the evaluation system of teacher performance salary, and certificates should be issued so that let the teachers' pay into a positive, harvest and side work for teaching harvest. Teachers on both sides need to have more communication about summary and feedback. Besides, the project requires the overall planning of students' school hours It is vital to strengthen the research of new equipment and new platform technology.

\section{CONCLUSION}

After the previous statistics, I obtain the results that cross-regional simultaneous teaching application pilot project is making contributions to solve the problem of unfair education in various areas. Meanwhile, the technology of the Two-way Broadband Satellite and the application of the Panoramic Learning Platform should be increased the effectiveness of use. And it is vital to notice the problem of teachers and students interact and class schedules in this project so that we can reach the balance between the public and facilities. In the future, we will further explore how to promote educational equity and try to find more efficient and lower cost solutions. Moreover, each country needs to tailor a solution which meets their own particular situation about educational fairness. By doing so we can make sure that the problem of unfair education caused by geography can be effectively solved.

\section{CONFLICT OF INTEREST}

The author declares no conflict of interest.

\section{AUTHOR CONTRIBUTIONS}

The only author contributes to all the work in this paper.

\section{ACKNOWLEDGMENT}

The author would like to thank Director Jie Zeng and Director Wenqiu Hong in National Center for Education Technology in Bejing, China, for their support in this project research. Meanwhile, thanks to Mr. Shimeng Wang who have consulted the literature in Manchester.

\section{REFERENCES}

[1] N. Li, Informatization Teaching of Optional Courses of Physical Education in Colleges and Universities, Springer, Cham, 2020, pp. 1675-1679.

[2] L. Y. Han and B. Xu, "Paying much attention to and improving fundamental teaching for cultivating innovative scientific researchers," J. Nanjing Univ. Aeronaut. Astronaut. Sci., vol. 4, 2008.

[3] I. G. Borisenko, D. N. Volodina, И. Г. Борисенко, and Д. Н. Володина, Educational Smart Technologies in the Educational Process, 2015

[4] X. J. Sun and Y. J. Guo, "The ways of educational targeted poverty alleviation for the poor in rural areas in chongqing," Educational Sciences: Theory Practice, vol. 18, no. 6, 2018.

[5] B. Shi, J. Shi, and P. Lu, "Problems and research emphases of higher education informatization in Chinese universities," in Proc. the 3rd International Conference on Economics and Management, Education, Humanities and Social Sciences (EMEHSS 2019), 2019.
[6] H. Ji and J. Qiu, "A study on the causes and countermeasures of the imbalance in the flow of compulsory education teachers in urban and rural areas in China," in Proc. the 2nd International Conference on Social Science, Public Health and Education (SSPHE 2018), 2019.

[7] H. Tang and A. Carr-Chellman, "Massive open online courses and educational equality in China: A qualitative inquiry," J. Educ. Technol. Dev. Exch., vol. 9, no. 1, Jun. 2016

[8] X. Lu, X. Lu, Y. Qiu, and Z. Tan, "The historical thread and analysis of teacher education policy in the past 70 years of new China," Can. Soc. Sci., vol. 15, no. 4, pp. 62-70, Apr. 2019.

[9] X. Qian and R. Smyth, Measuring Regional Inequality of Education in China: Widening Coast-Inland Gap or Widening Rural-Urban Gap?

[10] X. Sun and Y. Xu, "70 Years of basic education in China: Achievements and policies," Courses, Teach. Mater. Teach. Methods, vol. 2, 2019.

[11] F. Dai, Z. Yang, A. Ma, Y. Xia, and Y. Yang, "Analysis and research on the construction of cross-regional synchronous teaching mode based on panoramic wisdom classroom," Yunnan Educ. Primary Sch. Teach., vol. 12 , pp. 40-42, 2018.

[12] L. Saihe, "Research on the fairness of China's education system," Hist. Cult. Stud., no. 8, 2019.

[13] H. Zhou, G. Qiao, Y. Liao, A. Jing, J. Li et al., "Improving first-class talent training and innovation capabilities - Based on the interpretation of 'China's education modernization 2035," China Educ. Technol., vol. 391, pp. 9-17, 2019.

[14] X. Wang and Y. Zou, "SWOT analysis of clinic-style legal education in China," in Proc. the 3rd International Conference on Culture Education and Economic Development of Modern Society, 2019.

[15] Z. Liu, "Research on network fostering wisdom based on platform+ resource service system," China Educ. Technol., vol. 9860, 2019.

[16] H. Zhang, "Adding wings to the professional growth of teachers, and balancing the quality of education-Practice and research on cross-regional synchronous teaching in Dachuan district," Educ. Sci. Forum, vol. 8, no. 2, p. 2019, 2019.

[17] $\mathrm{X}$. Wu, "Cross-regional maker education research and training integration strategy and method research," Inserv. Educ. Train. Sch. Teach., no. 3, pp. 26-29, 2019.

[18] H. Li, "Point, chain, piece, block: The path and strategy of regional school alliance development," Local Educ., pp. 53-55, 2018.

[19] A. Avitzour, A. Keshet, and E. Agmon "Multi-spot satellite system for broadband communication," US Patent 20020032003A1, Jun. 2001.

[20] D. J. Bem, T. W. Wieckowski, and R. J. Zielinski, "Broadband satellite systems," IEEE Commun. Surv. Tutorials, vol. 3, no. 1, pp. 2-15, 2000

[21] Y. He, "Application of panoramic image technology in distance teaching system, " International Journal of Emerging Technologies in Learning, vol. 10, no. 6, 2015.

[22] Panoramic learning platform. [Online]. Available: http://www.qjxxpt.com/qjxxpt/Index/chanpin.html

[23] W. Y. Wong and P. Reimann, "Web based educational video teaching and learning platform with collaborative annotation," in Proc. 2009 Ninth IEEE International Conference on Advanced Learning Technologies, 2009, pp. 696-700.

[24] D. Zhao, A Survey and Analysis Report of the Pilot School of the Cross-Regional Synchronous Teaching Application Pilot Project of the Central Electrification Education Center, 2018.

[25] S. Fu, Research on the Guiding Strategy of Rural Teachers' Network and School-Based Integration Training, 2018.

Copyright (C) 2020 by the authors. This is an open access article distributed under the Creative Commons Attribution License which permits unrestricted use, distribution, and reproduction in any medium, provided the original work is properly cited (CC BY 4.0).

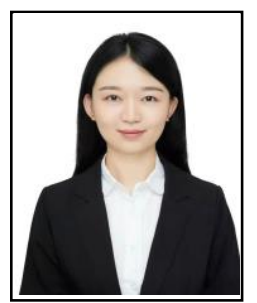

Sijia Kou was born in Heilongjiang Province, China on August 11, 1992. She got the BA degree in communication engineering from Beifang University of Nationalities in China from 2011 to 2015 and the MSc degree in communication engineering at the University of Manchester from 2015 to 2016.

She is as the research assistant of Network Department in National Center for Education Technology, Beijing, China. And she has worked as a part-time student services assistant at the University of Manchester Student Services Center in 2016.

Miss Kou's current work includes qualitative and quantitative research on education informatization, education poverty alleviation and network security. 